\title{
Myocardial bridges: morphological and functional aspects
}

\author{
A G Ferreira Jr, S E Trotter, B König Jr, L V Décourt, K Fox, E G J Olsen
}

Department of

Internal Medicine,

Faculty of Medicine of

University of State of

Pará, Belém-Pará,

Brazil

A G Ferreira Jr

Department of

Cardiac Pathology,

Royal Brompton

National Heart and

Lung Hospital, London

$S$ E Trotter

E G J Olsen

Department of

Anatomy, Institute of

Biomedical Science,

São Paulo University,

Brazil

B König Jr

Department of

Clinical Cardiology,

Heart Institute of

Faculty of Medicine of

São Paulo University,

Brazil

L V Décourt

Department of

Cardiology, Royal

Brompton National

Heart and Lung

Hospital, London

$\mathrm{K}$ Fox

Correspondence to

Dr A G Ferreira Jr,

Av Ricardo Borges 1600 ,

Av Ricardo Borges 1600,

Ananindeua-P
67000 , Brazil.

Accepted for publication

23 May 1991

\begin{abstract}
Objective-To assess the arrangement of myocardial bridges.

Design-A necropsy study of 90 consecutive hearts ( 56 male, 34 female).

Results-Myocardial bridges, either single or multiple, were seen in $\mathbf{5 0}$ $(55.6 \%)$ of the 90 hearts. The left anterior descending artery was the most commonly affected artery. Thirty five of the 50 hearts which contained in total 41 muscle bridges were dissected further with a magnifying glass. Two different types of muscle bridges could be identified. Thirty one of these 41 myocardial bridges were superficial, crossing the artery transversely towards the apex of the heart at an acute angle or perpendicularly. The remaining 10 myocardial bridges crossed the left anterior descending coronary artery and surrounded it by a muscle bundle that arose from the right ventricular apical trabeculae and crossed the artery transversely, obliquely, or helically before terminating in the interventricular septum.
\end{abstract}

Conclusions-The superficial type of myocardial bridge does not seem to constrict the artery during systole but the deep muscle bridges, by virtue of their relation with the left anterior descending coronary artery, could twist the vessel and thus compromise its diastolic flow. This may result in ischaemia.

Reyman in 1737 and Black in 1805 described an anatomical curiosity-the overlaying of the left anterior descending coronary artery by a muscular bridge. ${ }^{12}$ Since then there have been further reports ${ }^{34}$ and some investigators have described acute myocardial infarction in young patients in whom no coronary atherosclerosis was identifiable but in whom muscle bridges were found and the cause of the infarction was directly referrable to the myocardia bridge. ${ }^{56}$ There have been no detailed studies, however.

We have examined and classified myocardial bridges, particularly in terms of their relation to the left anterior descending coronary artery and have examined the haemodynamic implications these findings may have for ischaemic heart disease.

\section{Patients and methods}

We studied 90 hearts (56 male, 34 female) removed consecutively at necropsy. The individual ages ranged from a stillbirth to 84 years and in none was there a history of preceding established cardiac disease and death was not referrable to cardiac causes. Myocardial bridges were identified in 50 hearts. Thirty five of these hearts were examined further by hand lens dissection. Thirteen of the remaining 15 hearts, in which the left anterior descending coronary artery was directly related to a muscle bundle, were assessed histologically. After fixation, five were embedded in paraffin and $10 \mu \mathrm{m}$ sections were cut, and four were embedded in $8 \%$ celloidin and $100 \mu \mathrm{m}$ sections were cut. The sections were then stained by azan and resorcin fuschin and the azan and Weigert method respectively to demonstrate connective and elastic tissue. Segments of four hearts which included muscle bridges were cut at $60 \mu \mathrm{m}$ in a cryostat and stained by Sudan III to assess the adipose tissue interposed between the artery and the muscle bridge. The remaining two hearts were set aside for ultrastructural investigation.

\section{STATISTICAL TESTS}

We used Student's $t$ test for paired and unpaired samples with Fisher tests for variance and multiple comparison analysis. $P$ values $<0.05$ were considered significant.

\section{Results}

Thirty two of the 50 hearts that contained muscle bridges came from male subjects. In 35 hearts the bridges were single, affecting solely the left anterior descending coronary artery; 10 hearts contained two muscle bridges and five hearts contained three muscle bridges. These multiple muscle bridges affected either the same vessel or different coronary arteries or their branches. Significantly longer muscle bridges were seen in the 21-50 age group than in the hearts removed from subjects $0-20$ years (table 1). There was no statistical difference between the length of myocardial bridges in male and female subjects (table 2). Shorter muscle bridges were more common (table 3 and fig 1 ).

Table 1 Average (SD) length of myocardial bridges at different ages

\begin{tabular}{cl}
\hline Age $(y r)$ & Average length $(\mathrm{cm})$ \\
\hline $0-20$ & $1 \cdot 36(0 \cdot 479)$ \\
$21-50$ & $2.99(1.710)$ \\
$51-90$ & $2 \cdot 07(1.419)$ \\
\hline
\end{tabular}

Only the difference between the $0-20$ and $21-50$ age groups $(F=5 \cdot 29)$ was statistically significant $(p=0.0094)$. 
Table 2 Average (SD) length of the myocardial bridges in male and female hearts

\begin{tabular}{ll}
\hline & Average length $(\mathrm{cm})$ \\
\hline Male & $2 \cdot 16(1 \cdot 455)$ \\
Female & $2 \cdot 03(1.438)$ \\
\hline
\end{tabular}

$\mathrm{t}=\mathbf{0} \cdot 28 ; \mathrm{p}>0.05$

At hand lens dissection 41 muscle bridges were detected and were classified as superficial if the left anterior descending coronary artery ran on the interventricular groove and was crossed by the muscle bundle perpendicularly or at an acute angle before deviating to the apex of the heart (fig 2). This type was the more common and was identified in $31(75.6 \%)$ of the bridges. The remaining 10 muscle bridges $(24 \cdot 4 \%)$ were classified as deep: the left anterior descending coronary artery deviated towards the right ventricle and was deeply situated on the interventricular septum where it was crossed transversely, obliquely or helically by a longitudinal bundle arising from the apex of the right ventricle and inserting into the interventricular septum (figures $3 \mathrm{~A}$ and $\mathrm{B}$ ). Close scrutiny showed that some fibres surrounded the artery. This deep variant was seen less frequently and had longer muscle bundles than its superficial counterpart (table 3 ). Histological studies showed that there was no direct contact between the muscle bridge and the adventitial wall of the associated artery and that adipose, neural, and loose connective tissues were interposed between the muscle bridge and the related artery.

\section{Discussion}

The myocardial bridge is a distinctive anatomical entity whose pathophysiological role has evoked much controversy. Studies have shown that these muscular bands are present from birth ${ }^{78}$ and their development is closely associated with the growth of the adjacent artery. The incidence varies from report to report and seems to depend on the precision of the dissector. ${ }^{9}$ Our recorded incidence of $55.6 \%$ accords with other comparable studies. ${ }^{1011}$ The left anterior descending coronary artery is the most clinically important vessel that is affected by muscle bridges. Anatomical studies showed that most muscle bridges run between the proximal third and middle third of this vessel. ${ }^{12}{ }^{13}$ These findings

Figure 1 Graph showing incidence of muscle bridges and their length.

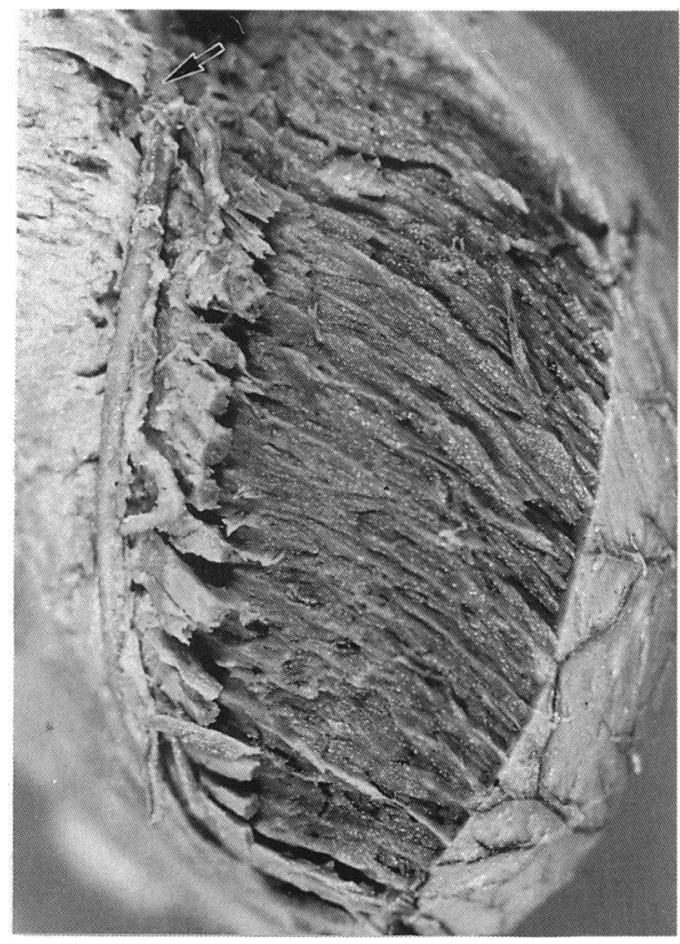

Figure 2 Dissected heart showing a $1 \cdot 2 \mathrm{~cm}$ superficial myocardial bridge overlying the left anterior descending coronary artery (arrow) which runs throughout its course on the interventricular groove.

accord with our own observations. The association of myocardial bridges with ischaemia is well established and symptoms have been relieved by surgical excision of the muscle bridge. ${ }^{14}{ }^{15}$ Hill et al showed that when the left anterior descending coronary artery runs underneath a muscle bridge it can be distorted in systole with a delay in diastolic relaxation. They also found that surgical resection of the muscle bridge often relieved the functional disturbance. ${ }^{16}$ However, some individuals with muscle bundles are symptom free. ${ }^{17}$ Various workers have attempted to classify the anatomical distribution of muscle bridges. Geiringer defined two types: in the first the left anterior descending coronary artery was sited deep in the interventricular groove with the muscle bridge surrounding it and in the second variant, which he considered to be more common, the muscle bridge arose from the trigonum fibrosum and invested the left anterior descending coronary artery as it passed to the apex of the heart. ${ }^{3} \mathrm{We}$ would classify these two types as superficial.

We consider the distinction between superficial and deep muscle bridges to be important in ischaemia and our classification may explain why some demonstrable muscle bridges do not cause symptoms. We showed that deep muscle bridges surround the left anterior descending coronary artery with helices of muscle fibres and we speculate that this may distort or compress the adjacent artery. Porstmann and Iwig recognised the usefulness of angiography in permitting in vivo visualisation of the myocardial bridge. ${ }^{18}$ Amplatz and Anderson too studied myocardial bridges angiographically. ${ }^{19}$ Angelini and his colleagues in their comprehensive review described how systolic 
Figure 3 (A) Dissected heart showing a $6 \cdot 2 \mathrm{~cm}$ deep myocardial bridge overlying the left anterior descending coronary artery. The path of the artery deviates from the interventricular groove towards the right ventricle where it is surrounded by a muscle bundle arising from the right ventricular apical trabeculae $(\star)$. (B) Close up view showing the oblique $(\mathrm{O})$, helical $(\mathrm{H})$ and transverse $(T)$ orientation of the surrounding muscle bundle.
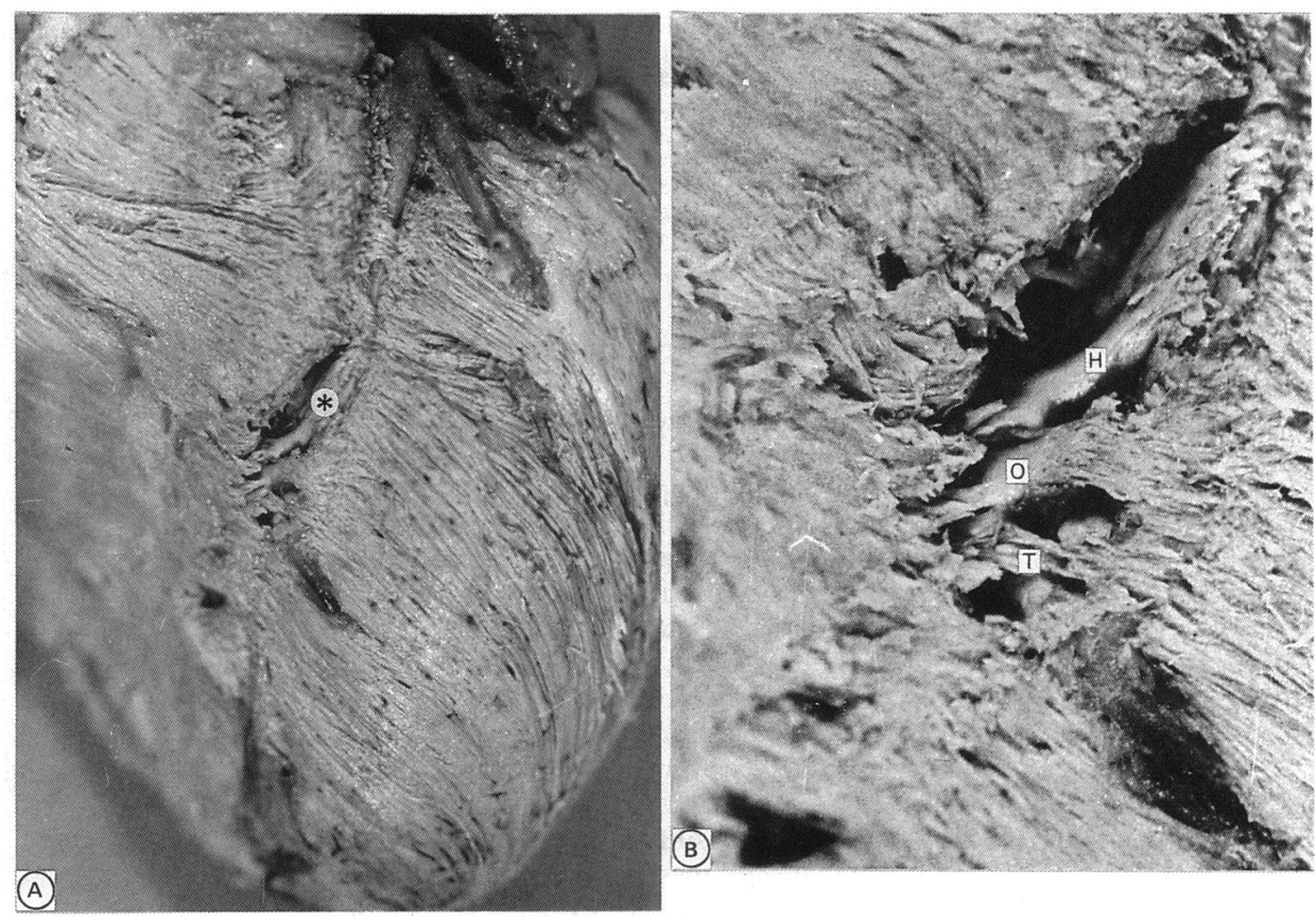

narrowing and kinking are useful angiographic evidence of myocardial bridges. ${ }^{20}$

Angelini et al commented on the disparity between the high incidence of myocardial bridges reported from anatomical studies and the lower angiographic incidence. Furthermore, they noted that angiographic evidence of myocardial bridges may depend on several factors, including the length of the bridge, the precise orientation of the bridge fibres in relation to the left anterior descending coronary artery, and the nature of the tissue interposed between the myocardial bridge and the adjacent artery. We believe that the disparity in the incidence reported from anatomical and angiographic studies depends on the length of the muscle bridge and that angiography detects only the deep myocardial bridges, which we noted were significantly larger and more likely to interfere with coronary flow. Ishimori et al reported that administration of glyceryl trinitrate to some patients unmasked angiographic narrowing of the left anterior descending coronary artery in systole, ${ }^{21}$ while the use of vasoactive drugs in patients with muscle bundles, has resulted in an episode of cardiac ischaemia in some subjects. ${ }^{22}{ }^{23} \mathrm{We}$ suggest that in patients with compression caused by the deep muscle bundle arrangement dilatation of the left anterior descending coronary artery may be unsuccessful.

We conclude that superficial or deep myocardial bridges form in utero at the time of cardiac development. In most individuals they do not cause symptoms but particularly in those with

Table 3 Average (SD) length of myocardial bridges according to path

\begin{tabular}{ll}
\hline & Average length $(\mathrm{cm})$ \\
\hline Superficial & $1.53(0.895)$ \\
Deep & $3.95(1.251)$ \\
\hline
\end{tabular}

$t=6.71 ; p<0.0001$. deep myocardial bridges, the anatomical relation of the myocardial fibres can distort the artery that can be identified angiographically. The possibility of myocardial bridges should be borne in mind in individuals with ischaemia but no evidence of coronary atherosclerosis.

A G F Jr was supported by CAPES from the Education Ministry of Brazil.

1 Reyman HC. Dissertatio de vasis cordis propriis. Haller, Bibl Anat 1737;2:366.

2 Black S. A case of angina pectoris with a dissection. Memoirs of the Medical Society of London 1805;6:41.

3 Geiringer E. The mural coronary. Am Heart J 1951;41: 359-68. Arteriosclerosis in the intramural and extramural portions of coronary in the human heart. Circulation 1956;13: $235-41$.

5 Vasan RS, Bahl VK, Rajani M. Myocardial infarction associated with a myocardial bridge. Int $J$ Cardiol 1989;25:240-1.

6 Bestetti RB, Costa RS, Zucolotto S, Oliveira JSM. Fatal outcome associated with autopsy proven myocardial bridging of the left anterior descending coronary artery. Eur Heart $J$ 1989;10:573-6.

7 von Polácek $P$. Relation of myocardial bridges and loops on the coronary arteries to coronary occlusions. Am Heart $J$ 1961;61:44-52.

8 Visscher DW, Miles BL, Waller BF. Tunnelled ("bridged") left anterior descending coronary artery in a newborn left anterior descending coronary artery in a newborn
without clinical or morphologic evidence of myocardial without clinical or morphologic evidence of myocar
ischaemia. Cathet Cardiovasc Diagn 1983;9:493-6.

9 von Polácek $P$, Zechmeister $A$. The occurrence and significance of myocardial bridges and loops on coronary arteries. Opuscola Cardiologica. Acta Facultatis Medicae Universitatis Brunensis, Brno, 1968

10 Hansen BF. Myocardial covering on epicardial coronary arteries. Prevalence, localization and significance. Scand $J$ Thorac Cardiovasc Surg 1982;16:151-5.

11 Ishii T, Hosoda Y, Osaka T, et al. The significance of myocardial bridge upon atherosclerosis in the left anterior descending coronary artery. $J$ Pathol 1986;148:279-91.

12 Bezerra AJC, Prates JC, Didio LJA. Incidence and clinical significance of bridges of myocardium over the coronary arteries and their branches. Surg Radiol Anat 1987;9: 273-80.

13 Reig J, Loncan MP, Martin S, Binia M, Petit M, Domenech JM. Ponts myocardiques. Incidence et relation avec certaines variables coronariennes. Arch Anat Histol certaines variables cor

14 Marshall ME, Headley RN. Intramural coronary artery as a cause of unstable angina pectoris. South Med J 1978; 71:1304-6. coronária descendente anterior com trajeto intramiocár-
4 Edwards JC, Burnsides G, Swarm RL, Bansing AI.

15 Teixeira JR, Aldrovando J, Santos PSF, et al. Artéria 
dico: estudo anatômico e implicações cirúrgicas. Arq Bras Cardiol 1979;33(suppl 1):334-9.

16 Hill RC, Chitwood WR Jr, Bashore TM, Sink JD, Cox JL, Wechsler AS. Coronary flow and regional function before and after supraarterial myotomy for myocardial bridging. Ann Thorac Surg 1981;31:176-81.

17 Loures JBL, Souza JEMR, Pimentel WAF, et al. Estudo hemodinâmico e metabólico de pacientes com ponte miocárdica na artéria descendente anterior. Arq Bras Cardiol 1978;31:159-65.

18 Porstmann W, Iwig J. Die intramurale Koronarie im Angiogramm. Fortschr Röntgenstr 1960;92:129-32.

19 Amplatz $K$, Anderson $R$. Angiographic appearance of myocardial bridging of the coronary artery. Invest Radiol
1968;3:213-5.

20 Angelini $P$, Trivellato $M$, Donis J, Leachman RD. Myocardial bridges: a review. Prog Cardiovasc Dis 1983;26:75-88.

21 Ishimori T, Raizner AE, Chahine RA, Awdeh M, Luchi RJ. Myocardial bridges in man: clinical correlations and angiographic accentuation with nitroglycerine. Cathet Cardiovasc Diagn 1977;3:59-65.

22 Pichard AD, Casanegra P, Marchant E, Rodriguez JA. Abnormal regional myocardial flow in myocardial bridging of the left anterior descending coronary artery. $A m$ Cardiol 1981;47:978-82.

23 Carvalho VB, Macruz R, Décourt LV, et al. Hemodynamic determinants of coronary constriction in human myocardial bridges. Am Heart J 1984;108:73-80.

\section{PLANTS IN CARDIOLOGY}

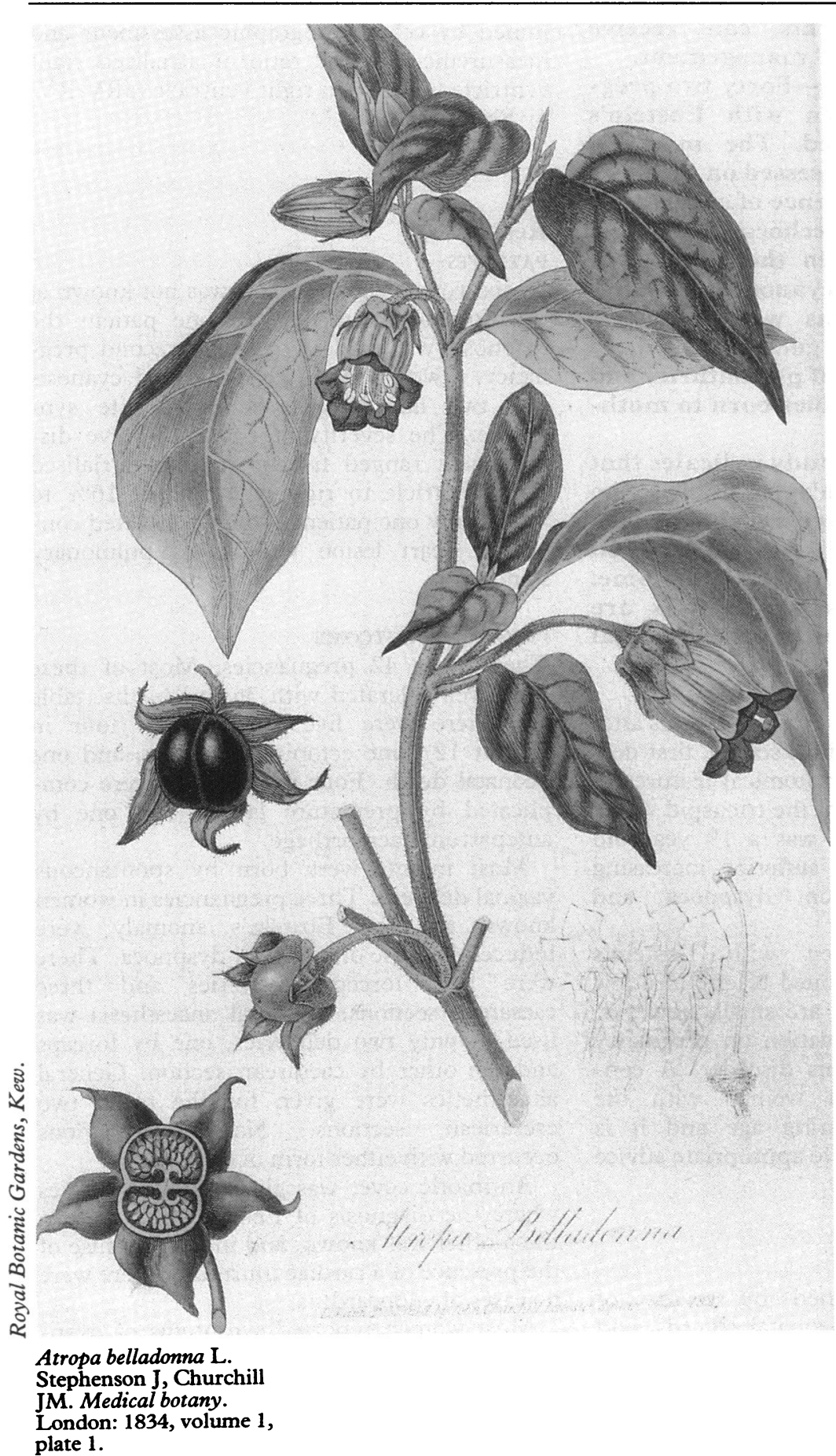

\section{Atropine}

Atropine is obtained from the leaf and berries of Atropa belladonna (Solanaceae), the deadly nightshade, an herbaceous plant of central and southern Europe. It is very poisonous and Linnaeus named it after one of the Fates, Atropus, who cut the thread of life. Though it was popular for deliberate poisoning it was avoided medicinally except for external use. The leaf was used to dilate the pupil for cataract extraction, and as a liniment for rheumatism. A large pupil was once held to enhance female beauty, hence belladonna. Nightshade is a curious word which may allude to the narcotic property of the black berries.

Atropine was isolated in 1831, and in 1867 von Bezold showed that it blocked the cardiac effects of vagal stimulation. Sir James Mackenzie (1853-1925) used it widely in his arrhythmia work. He showed that it would revert partial though not complete heart block. He also studied its effect on the rate in digitalised patients with atrial fibrillation and submitted a paper on this subject to Heart. The editor, Thomas Lewis, rejected it and this infuriated Mackenzie who replied "You might as well put upon the forefront of the journal 'No articles will be accepted which are not in accordance with the (temporary) beliefs of the Editor' " (McMichael J, Journal of the Royal College of General Practitioners 1981;31:402-6). Atropine was employed with minimal success to prevent Stokes-Adams attacks and it was little used in cardiology until the introduction of cardiopulmonary resuscitation.

The family Solanaceae is distributed worldwide and has over 2000 species, which include tomato, potato, and tobacco. The invaluable drug hyoscine (scopolamine) is found in Mandragora officinarum (mandrake) and in Datura stramonium (thornapple). Nowadays atropine and hyoscine are obtained commercially from an Australian tree of this family Duboisia myoporoides (corkwood) whose narcotic property was discovered by the aboriginals. 